\title{
Use of Gosereline in the preservation of fertility in young women with breast cancer: a bibliographical review
}

\author{
Flávio Chagas de Albuquerque1*, Iolanda Matias Gomes², Luiz Alberto Mattos², Márcia Silva de Oliveira³ \\ ${ }^{1}$ Hospital da Mulher do Recife, Recife, PE, Brazil \\ 2Universidade Federal de Pernambuco (UFPE), Hospital das Clínicas (HC), Recife, PE, Brazil \\ ${ }^{3}$ Universidade Federal de Pernambuco (UFPE), Departamento de Ginecologia, Recife, PE, Brazil
}

\begin{abstract}
The fertility preservation in cancer patients is a concern that mobilizes researchers worldwide, since ovarian failure after chemotherapy is an important issue. Several methods have been developed to increase the chances of pregnancy after cancer treatment, such as the use of Gosereline, a Gonadotrophin-Releasing Hormone Agonist adjuvant to chemotherapy, for ovarian protection. A review of the literature was done, and after exclusion criteria, eight studies were selected. In general, all evaluated studies discusses that Goserelin is a good option for reducing the risk of premature ovarian failure, since it is able to preserves ovarian function. Moreover, GnRH agonist used concomitantly with chemotherapy in a breast cancer patient appears to protect against the harmful effects of chemotherapy, with a high probability of pregnancy, improved fertility and long-term survival. Nevertheless, all studies agree that further prospective and randomized studies are required.
\end{abstract}

Keywords: GnRH agonist; fertility preservation; ovarian failure; chemotherapy.

\section{Introduction}

The estimated risk of breast cancer in Brazil is 56.20/100,000 women, according to INCA - National Cancer Institute. In addition to environmental, dietary and alcohol consumption, mutations in the BRCA1 and BRCA2 genes are important contributing factors for cancer development. ${ }^{2}$ Since women of reproductive age and without defined offspring are the main cancer patients, it is an actual clinical challenge.

It is widely known that there is an age-related decline in female fertility after 35 years old until menopause, around age $50 .{ }^{3}$ Of the 300,000 viable oocytes in menarche, only about 500 primordial follicles will attain ovulation. At menopause, the ovary will be formed by dense stroma and rare oocytes. ${ }^{4}$

The fertility preservation in cancer patients is a concern that mobilizes researchers worldwide. ${ }^{5}$ Several methods have been developed to increase the chances of becoming pregnant after cancer treatment, ${ }^{6}$ such as cryopreservation, in vitro fertilization and the use of medications for ovarian protection during chemotherapy.

Follicle Stimulating Hormone (FSH) and Inhibin $\mathrm{B}^{7,8}$ can be detected in peripheral blood, with normal normal value ranges, respectively, from 3.0 to $15.0 \mathrm{IU},{ }^{9}$ and around $100 \mathrm{pg} / \mathrm{ml}$. It is believed that Inhibin B levels can predict the ovarian reserve, even before the FSH increase. ${ }^{10}$ Antimülerian Hormone (AMH) has emerged as the most reliable marker for ovarian reserve, since postmenopausal women have undetectable levels of it. ${ }^{11}$ Its normal values are around $2.0 \mathrm{ng} / \mathrm{ml}$.

The evaluation of ovarian volume and antral follicles counting by transvaginal ultrasonography (TV USG), may be an indicator of reproductive function. ${ }^{12}$ The measure of ovarian volume is considered highly predictive for poor reproductive prognosis, if is less than $3 \mathrm{~cm}^{3}$. It is suggested that the ovarian volume of the woman at menacme is directly proportional

Financial support: This work was finished whith resources of own authors.

Conflicts of interest: The authors declare no conflicts of interest.

Submitted: April 17, 2017.

Accepted: November 21, 2017

The study was carried out at the Hospital das Clínicas (HC), Universidade Federal de Pernambuco (UFPE), Recife, PE, Brazil.

Copyright Albuquerque et al. This is an Open Access article distributed under the terms of the Creative Commons Attribution License, which permits unrestricted use, distribution, and reproduction in any medium, provided the original work is properly cited. 
to the remaining follicular population. ${ }^{13}$ But the value of this measure should not be used isolated, but rather should be accompanied by other markers of the ovarian reserve. ${ }^{13}$ It is known that the more primordial follicles are present, the better is the reproductive capacity. ${ }^{14-16}$ The minimum count of 20 follicles in both ovaries is associated with better reproductive prognosis. ${ }^{16}$ Age, however, is closely related to these parameters. ${ }^{14,17}$

The main damages associated with chemotherapy on the female gonad vary according to the treatment. ${ }^{18,19}$ Alkylating agents are considerade highly gonadotoxic, inducing oocyte depletion and hormone deficiency. ${ }^{20}$ Its effects may be transient like amenorrhea, or permanent causing premature ovarian failure and sterility. ${ }^{21,22}$

To preserve the ovaries from these toxic effects, many authors propose the concomitant use of Gonadotrophin-Releasing Hormone Agonist (GnRH). ${ }^{19}$ However, GnRH is considered a high-cost drug, being inaccessible to a large part of the population.

$\mathrm{GnRH}$ is a decapeptide typically produced in a pulsatile manner, which induces suppression of the hypothalamic-pituitary-gonadal axis and return the ovary to a more quiescent state by increasing the Luteinizing hormone (LH) and $\mathrm{FSH}^{21} \mathrm{GnRH}$ also reduces ovarian blood flow, causing a decrease in the amount of chemotherapy accessing ovaries. ${ }^{23}$ The LHRH (Luteinizing Hormone-Releasing Hormone) agonist Gosereline, a synthetic drug that acts on the pituitary gland in a non-pulsatile way, also results in hypoestrogenism and ovarian protection. . $^{21,24}$

$\mathrm{GnRH}$ administration is indicated for women up to 40 years old in breast cancer chemotherapy, besides other indications. ${ }^{19}$ Gosereline is initiated up to 14 days before the start of chemotherapy, and maintained at 28-day intervals, until two weeks after the end of treatment. ${ }^{14,25}$ One of its adverse effects is the reduction of bone mass. ${ }^{26}$ Because of the long-term effects of GnRH analogues, these are not clearly elucidated and are not endorsed in prospective research by the Ethics Committees. ${ }^{27}$

This study focuses on the use of the analogue in young women with breast cancer, through a review of this application.

\section{Methods}

A review of the literature was conducted by PubMed database, accessing articles published in English language, during the last ten years until April 2016, using the following keywords: Breast cancer, Gosereline and Fertility, limiting the results to the title or the abstract. Other works that did not fit the purpose of the review were excluded from the study.

\section{Results}

Sixteen articles were selected, of which eight were excluded according the criteria: one article was in the Japanese language, the other approached the quality of life in patients with breast cancer, one study used the analogue Triptorelin. Another study was excluded because its evaluation of the impact of temporary ovarian suppression on disease-free survival. A case report was also excluded. The last three exclusions were a letter to the reader.

\section{Discussion}

Urruticoechea et al. ${ }^{5}$ conducted a prospective study to evaluate breast cancer patients who undergone chemotherapy, where 50 of them had post-treatment follow-up of 43 months. Of the 50 patients evaluated, $45(90 \%)$ recovered menstrual cycles (43 during the first year of follow-up and 2 after the second year of follow-up). The median time to resumption of menstrual cycles was 4 months after the last course of chemotherapy with a range of 0-17 months. Of these 45 patients, 34 had FSH, LH and estrogen dosed. Only 10 patients attempted to become pregnant, seven were successful, and one had gestations in subsequent years.

Authors noticed that only 10 women tried to conceive after chemotherapy, probably due to those patients with estrogen-positive receptors were advised to delay pregnancy and prolong ovarian suppression, based on the emerging data presented in this approach. ${ }^{28}$ Although conscious that gestation may not interfere with the course of the disease, it is a concern the use of Gosereline and a reduction in the action of Tamoxifen. ${ }^{27}$

This study used estrogen and LH as a marker of ovarian function, but did not mention the moment of the dosage, nor was there any conclusions regarding the correlation of hormonal levels and fertility. A weak point was sample size. Even so, authors concluded that Gosereline is a good option for reducing the risk of premature ovarian failure, but that is necessary case-control studies.

Badawy et al., ${ }^{27}$ in a prospective randomized study, evaluated 80 breast cancer patients indicated for chemotherapy, aged 18-40 years, who received GnRH analogue in monthly standard dose for 6 months. Doses of FSH, LH, estradiol, progesterone and prolactin were performed monthly. Ultrasonography was used for ovarian and endometrial measurements. 
Among the parameters used to measure ovarian function, only FSH was significantly lower in the group receiving the analog. Of the sample, 27 (68.2\%) returned to spontaneous ovulation within 3-8 months after the end of treatment. In the control group $10(25.6 \%)$ reestablished the ovulation $(\mathrm{P}<0.001)$. The authors conclude that the use of $\mathrm{GnRH}$ analog preserves ovarian function, but that long-term studies are necessary.

In a review paper published in 2009,30 Sonmezer and Oktay ${ }^{24}$ investigate the protective role of the GnRH analogue against the damages caused by chemotherapy and conclude that there are no prospective and randomized studies that can demonstrate their efficacy.

In a 2010 publication, Edgard Petru ${ }^{31}$ addresses the fertility preservation in young breast cancer patients who need to postpone motherhood. The author investigates four randomized trials with GnRH analogues. ${ }^{28-30}$ Treatment of GnRH was performed over a 2-year period in one of the studies, ${ }^{30}$ while in the other three, there was only an ovarian blockage during single chemotherapy. ${ }^{27,29,30}$ Two studies did not include early pregnancy rates. The author also discusses alternative techniques of ovarian removal by videolaparoscopy and reimplantation after 2 years of chemotherapy. Another possibility was oocyte cryopreservation.

The author states that pregnancy after breast cancer treatment does not worsen the prognosis but there is a bias to be considered as young women tend to have healthy children. ${ }^{28}$ More studies of ovarian preservation are necessary, knowing that the $\mathrm{AMH}$ may be the best marker to estimate the ovarian reserve.

Wong et al.,32 in 2012, analyzed the GnRH analogue Gosereline effect in a concomitant use with chemotherapy in young breast cancer patient, in a total of 125 women taking Gosereline every 28 days. Of these, 30 women became pregnant. The sample group was very uniform and that menstrual reestablishment reached up to 43 months. They conclude that the GnRH agonist used concomitantly with chemotherapy in a breast cancer patient is associated with a low risk of amenorrhea induced by the harmful effects of chemotherapy and a high probability of pregnancy.

Kim et al. ${ }^{33}$ in a prospective study to determine the impact of the GnRH agonist concomitant with chemotherapy reported that the evidence of the ovarian protective role of the agonist has conflicting data in randomized trials. ${ }^{32,33}$ The authors conducted the study at the Samsung Medical Center Cancer Center in Seoul in Korea with women between the ages of 20 and 40 eligible for chemotherapy.

Of the 1073 patients studied, 124 patients received the GnRH analog before and during adjuvant chemotherapy, every 28 days. Two GnRH analogs were used: leuprorelin 3.75mg (105 patients) and 3.6mg Gosereline (19 patients). The author reports that different forms of chemotherapy regimens were prescribed according to the disease stage and treatment period and there was no difference between the groups. Patients treated with GnRH analogue showed significantly better results in non-relapsing disease than those treated with chemotherapy alone $(p=0.034)$, although the survival rate was not different $(p=0.413$ ). The authors conclude that chemotherapy with $\mathrm{GnRH}$ analogue for young patients with breast cancer is an option for fertility preservation.

Recchia et al., ${ }^{34}$ analyzed 200 breast cancer patients treated with with GnRH analogue during chemotherapy. ${ }^{34}$ One hundred patients were selected to receive a quarterly schedule of Goserelinea at the dose of $11.4 \mathrm{mg}$, for 5 years, supplement of vitamin $\mathrm{D}$, calcium and bisphosphonate. The authors concluded that this protocol was effective for ovarian preservation and was associate with survival improvement outcomes.

In 2015, Lúcia Del Mastro et al. ${ }^{35}$ reported a meta-analysis with nine studies involving the a positive outcome in an association of LH-RH with tamoxifen and aromatase inhibitors. But in 2014, two large phase III trials were published and clarified the related doubts about the actual efficacy of ovarian preservation and pregnancy rate.

In the POEMS (Prevention of early menopause study) study, 257 selected women on chemotherapy received GnRH analog. The conclusion was that patients treated with analogue had improved disease-free survival rates $(p=0.04)$ and overall survival $(p=0.05)$. The authors concluded by recommending the temporary suppression of LH-RH as a valid strategy for patients with negative hormone receptor, but does not demonstrate a direct relation with fertility preservation.

Moore et al., ${ }^{36}$ underwent a phase III clinical trial with estrogen and progesterone negative hormone receptor with patients between 18 and 49 years old, divided randomly into two groups according to Gosereline use. They found that the rate of ovarian failure was $8 \%$ in the Gosereline group compared to $22 \%$ in the group without. The percentage of pregnancy was higher in the first group $(21 \%$ vs. $11 \%, p=0.03)$, as well as better disease-free survival $(p=0.04)$ and overall survival $(p=0.05)$. The authors stated that treatment with the GnRH agonist during chemotherapy appears to protect against ovarian failure, reduced the risk of early menopause, and improved fertility.

\section{References}

1. Instituto Nacional de Câncer José Alencar Gomes da Silva. Estimativa 2016: incidência de câncer no Brasil [Internet]. Rio de Janeiro: INCA; 2015 [cited 2016 July]. Available from: http://www.inca.gov.br/estimativa/2016/estimativa-2016-v11.pdf 
2. Yoshida K, Miki Y. Role of BRCA1 and BRCA2 as regulators of DNA repair, transcription, and cell cycle in response to DNA damage. Cancer Sci. 2004;95(11):866-71. http://dx.doi.org/10.1111/j.1349-7006.2004.tb02195.x.

3. Silva HMS, Junqueira JPC, Pacheco F, Megale L, Poggiale P. Gravidez depois dos 40. Belo Horizonte; 2004 [cited 2007 May 20 ]. Available from: http://www.materdei.com.br/qvc/informacoes/gravidez_40.jsp

4. Freitas F, Martins-Costa SH, Ramos JGL, Magalhães JA. Rotinas em obstetrician. 6th ed. Porto Alegre: Art Med; 2011.

5. Urruticoechea A, Arnedos M, Walsh G, Dowsett M, Smith IE. Ovarian protection with goserelin during adjuvant chemotherapy for pre-menopausal women with early breast cancer (EBC). Breast Cancer Res Treat. 2008;110(3):411-6. http://dx.doi.org/10.1007/ s10549-007-9745-y.

6. Maltaris T, Seufert R, Fischl F, Schaffrath M, Pollow K, Koelbl H, et al. The effect of cancer treatment on female fertility and strategies for preserving fertility. Eur J Obstet Gynecol Reprod Biol. 2007;130(2):148-55. http://dx.doi.org/10.1016/j.ejogrb.2006.08.006.

7. De Vet A, Laven JSE, de Jong FH, Themmen APN, Fauser BCJM. Antimüllerian hormone serum levels: a putative marker for ovarian aging. Fertil Steril. 2002;77(2):357-62. http://dx.doi.org/10.1016/S0015-0282(01)02993-4.

8. Avril C. L'ovocyte: avancées fondamentales et thérapeutiques: peut-on prédire la qualité ovocytaire par l'échographie? J Gynecol Obstet Biol Reprod. 2006;35(2):42-3. http://dx.doi.org/10.1016/S0368-2315(06)76440-7.

9. Chuang CC, Chen CD, Chao KH, Chen SU, Ho HN, Yang YS. Age is a better predictor of pregnancy potential than basal folliclestimulating hormone levels in women undergoing in vitro fertilization. Fertil Steril. 2003;79(1):63-8. http://dx.doi.org/10.1016/ S0015-0282(02)04562-4.

10. Seifer DB, MacLaughlin DT. Mullerian Inhibiting Substance in an ovarian growth factor or emerging clinical significance. Fertil Steril. 2007;88(3):539-46. http://dx.doi.org/10.1016/j.fertnstert.2007.02.014.

11. Visser JA, de Jong FH, Laven JSE, Themmen APN. Anti-Müllerian hormone: a new marker for ovarian function. Reproduction. 2006;131(1):1-9. http://dx.doi.org/10.1530/rep.1.00529.

12. Maheshwari A, Fowler P, Bhattacharya S. Assessment of ovarian reserve - should we perform tests of ovarian reserve routinely? Hum Reprod. 2006;21(11):2729-35. http://dx.doi.org/10.1093/humrep/del188.

13. Tufan E, Elter K, Durmusoglu F. Assessment of reproductive ageing patterns by hormonal and ultrasonographic ovarian reserve tests. Hum Reprod. 2004;19(11):2484-9. http://dx.doi.org/10.1093/humrep/deh448.

14. Kovacs P. Preserving ovarian function after breast cancer treatment. Fertil Steril. 2009;91(3):694-7.

15. Brougham MF, Wallace WHB. Subfertility in children and young people treated for solid and haematological malignancies. Br J Haematol. 2005;131(2):143-55.

16. Del Mastro L, Catzeddu T, Boni L, Bell C, Sertoli MR, Bighin C, et al. Prevention of chemotherapy induced menopause by temporary ovarian suppression with goserelin in young, early breast cancer patients. Ann Oncol. 2006;17(1):74-8. http://dx.doi.org/10.1093/ annonc/mdj029.

17. Wallace $W H$, Kelsey TW. Ovarian reserve and reproductive age may be determined from measurement of ovarian volume by transvaginal sonography. Hum Reprod. 2004;19(7):1612-7. http://dx.doi.org/10.1093/humrep/deh285.

18. Chang HJ, Suh CS. Fertility preservation for women with malignancies: current developments of crypreservation. J Gynecol Oncol. 2008;19(2):99-107. http://dx.doi.org/10.3802/jgo.2008.19.2.99.

19. Blumenfeld Z. GnRH-agonists in fertility preservation. Curr Opin Endocrinol Diabetes Obes. 2008;15(6):523-8. http://dx.doi. org/10.1097/MED.0b013e32831a46e9.

20. Chen SV, Yang YS. Slow freezing or vitrification of oocytes: their effects on survival and meiotic spindles, and the time schedule for clinical practice. Taiwan J Obstet Gynecol. 2009;48(1):15-20.

21. Maltaris T, Beckmann MW, Dittrich R. Fertility preservation for young female cancer patients. In Vivo. 2009;23(1):123-30.

22. Georgescu ES, Goldberg JM, du Plessis SS, Agarwal A. Present and future fertility preservation strategies for female cancer patients. Obstet Gynecol Surv. 2008;63(11):725-32. http://dx.doi.org/10.1097/OGX.0b013e318186aaea.

23. Cabrera R, Stadtmauer L, Mayer J, Gibbons W, Oehninger S. Follicular phase serum levels of luteinizing hormone do not influence delivery rates in in vitro fertilization cycles down-regulated with a gonadotropin-releasing hormone agonist and stimulated with recombinant follicle-stimulating hormone. Fertil Steril. 2005;83(1):42-8. http://dx.doi.org/10.1016/j.fertnstert.2004.06.050.

24. Sonmezer M, Oktay K. Fertility preservation in female patients. Hum Reprod Update. 2004;10(3):251-66. http://dx.doi.org/10.1093/ humupd/dmh021.

25. Albain K, Barlow W, O'Malley F, Siziopikou K, Yeh IT, Ravdin P, et al. Concurrent (CAFT) versus sequential (CAF-T) chemohormonal therapy (cyclophosphamide, doxorubicin, 5-fluorouracil, tamoxifen) versus $T$ alone for postmenopausal, node-positive, estrogen (ER) and/or progesterone (PgR) receptor-positive breast cancer: mature outcomes and new biologic correlates on phase III intergroup trial 0100 (SWOG-8814). In: Proceedings of the San Antonio Breast Cancer Symposium; 2004; San Antonio, Texas, USA. Texas: SABCS; 2004.

26. Baum M, Hackshaw A, Houghton J, Rutqvist, Fornander T, Nordenskjold B, et al. Adjuvant goserelin in premenopausal patients with early breast cancer: results from the ZIPP study. Eur J Cancer. 2006;42(7):895-904. http://dx.doi.org/10.1016/j.ejca.2005.12.013.

27. Badawy A, Elnashar A, El-Ashry M, Shahat M. Gonadotropin-releasing hormone agonists for prevention of chemotherapy-induced ovarian damage: prospective randomized study. Fertil Steril. 2009;91(3):694-7. http://dx.doi.org/10.1016/j.fertnstert.2007.12.044. 
28. Gerber B, Stehle H, Ricardo F, Maass N, Fischer D, Sommer HL, et al. ZORO: a prospective randomized multicenter study to prevent chemotherapy-induced ovarian failure with the $\mathrm{GnRH}$-agonist goserelin in young hormone-insensitive breast cancer patients receiving anthracycline containing (neo-)-adjuvant chemotherapy (GBG 37). J Clin Oncol. 2009;15(Suppl):526.

29. Sverrisdottir A, Nystedt M, Johansson H, Fornander T. Adjuvant goserelin and ovarian preservation in chemotherapy treated patients with early breast cancer: results from a randomised trial. Breast Cancer Res Treat. 2009;117(3):561-7. http://dx.doi. org/10.1007/s10549-009-0313-5.

30. Oktay K, Buyuk E, Libertella N, Akar M, Rosenwaks Z. Fertility preservation in breast cancer patients: a prospective controlled comparison of ovarian stimulation with tamoxifen and letrozole for embryo cryopreservation. J Clin Oncol. 2005;23(19):4347-53. http://dx.doi.org/10.1200/JCO.2005.05.037.

31. Petru E. Fertility preservation and infertility treatment in breast cancer patients. Wien Med Wochenschr. 2010;160(19-20):487-92. http://dx.doi.org/10.1007/s10354-010-0833-y.

32. Wong M, O'Neill S, Walsh G, Smith IE. Goserelin with chemotherapy to preserve ovarian function in pre-menopausal women with early breast cancer: menstruation and pregnancy outcomes. Ann Oncol. 2013;24(1):133-8. http://dx.doi.org/10.1093/annonc/ mds250.

33. Kim J, Kim M, Lee JH, Lee H, Lee SK, Bae SY, et al. Ovarian function preservation with GnRH agonist in young breast cancer patients: does it impede the effect of adjuvant chemotherapy? Breast. 2014;23(5):670-5. http://dx.doi.org/10.1016/j.breast.2014.07.005.

34. Recchia F, Necozione S, Bratta M, Rosselli M, Guerriero G, Rea S. LH-RH analogues in the treatment of young women with early breast cancer: long-term follow-up of a phase II study. Int J Oncol. 2015;46(3):1354-60. http://dx.doi.org/10.3892/ijo.2014.2811.

35. Del Mastro L, Rossi G, Lambertini M, Poggio F, Pronzato P. New insights on the role of luteinizing hormone releasing hormone agonists in premenopausal early breast cancer patients. Cancer Treat Rev. 2016;42:18-23. http://dx.doi.org/10.1016/j.ctrv.2015.11.002.

36. Moore HC, Unger JM, Phillips KA, Boyle F, Hitre E, Porter D, et al. POEMS/S0230 Investigators. Goserelin for ovarian protection during breast-cancer adjuvant chemotherapy. N EngI J Med. 2015;372(10):923-32. http://dx.doi.org/10.1056/NEJMoa1413204.

\section{*Correspondence}

Flávio Chagas de Albuquerque

Hospital da Mulher do Recife

$\mathrm{Br} 101, \mathrm{~S} / \mathrm{N}$, Curado

CEP 50790-640, Recife, PE, Brazil

Tel.: +55 (81) 99993-0099

E-mail: flaviocalbuquerque@gmail.com

\section{Authors information}

FCA - Gynecologist and Obstrtrician of the Women's Hospital of Recife. IMG - Gynecologist Surgery of the Clinics Hospital of the University of Pernambuco. LAM - Clinical Oncologist os the Hospital of the Clinics of the Federal University Of Pernambuco. MSO - Professor of the Departmenr of Gynecology of the Faculty of Medicine of the Federal University of Pernambuco.

\section{Authors contribution}

FAC - Author and literature reviewer. IMG - Methodology Advisor. LAM - Discussion Advisor. MSO - Reviewer. 